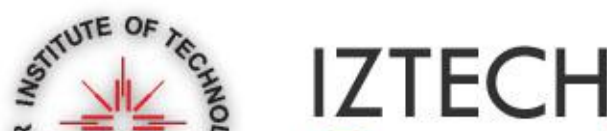 \\ Open Access Articles
}

Systematic tuning the hydrodynamic diameter of uniformed fluorescent silica nanoparticles

The IZTECH Faculty has made this article openly available. Please share how this access benefits you. Your story matters.

\begin{tabular}{|l|l|}
\hline Citation & $\begin{array}{l}\text { Durgun, G, Ocakoglu, K, Ozcelik S, "Systematic tuning the } \\
\text { hydrodynamic diameter of uniformed fluorescent silica } \\
\text { nanoparticles" Journal of Physical Chemistry @ 2011Elsevier }\end{array}$ \\
\hline As Published & http:// 10.1021/jp204323d \\
\hline Publisher & Elsevier \\
\hline Version & PUBLISHED ARTICLE \\
\hline Accessed & FRI JULY 5 14:21:23 GMT 2013 \\
\hline Citable Link & http://hdl.handle.net/11147/ \\
\hline Terms of Use & $\begin{array}{l}\text { Article is made available in accordance with the publisher's } \\
\text { policy and may be subject to Turkish copyright law. Please } \\
\text { refer to the publisher's site for terms of use. }\end{array}$ \\
\hline Detailed Terms & \\
\hline
\end{tabular}




\title{
Systematic tuning the hydrodynamic diameter of uniformed fluorescent silica nanoparticles
}

\author{
Gulay Durgun, Kasim Ocakoglu, Serdar Ozcelik \\ Izmir Institute of Technology, Department of Chemistry, 35430 Urla, Izmir, Turkey
}

\begin{abstract}
We report a facile method for systematic tuning the hydrodynamic diameter of uniformed fluorescent silica particles in the size range from 12 to $465 \mathrm{~nm}$. Dynamic light scattering and electron microscopy studies demonstrate that the hydrodynamic size distribution of the silica particles is uniform. We show that the initial amounts of ethanol and ammonia are essential to tune the size of these particles. The hydrodynamic diameter of such a particle increases as the amount of ammonia is increased. On the other hand, an increase in the amount of ethanol leads to the formation of smaller particles. Higher initial amount of ethanol yield an increase in the concentration of ethoxide ions and a decrease in the concentration of hydroxide ions. Such control over the concentration of hydroxide ion, which is responsible for the formation of siloxane bonds, causes a controlled-growth of the silica particles, resulting in precise tuning the hydrodynamic size. We confirm that a linear relationship exists between size and brightness of particles, demonstrating that the amount of dye molecules in such particles can be regulated by the presented method. We prove that the silica network provides protection for dye molecules encapsulated in particles against solvents, fluorescence quenchers, and unfavorable $\mathrm{pH}$ of environments. Moreover, the fluorescent silica particles with the size of 12,50 and $250 \mathrm{~nm}$ were found to not be cytotoxic against the epithelial cell lines of MCF7 and PC3 even when the dosage levels up to $1.0 \mathrm{mg} / \mathrm{ml}$ and incubation periods up to 72 hours were applied.
\end{abstract}

Key words: fluorescent silica nanoparticles, systematic preparation, size control, cell viability, MCF7 and PC3 cell lines.

Corresponding author: Serdar Ozcelik, serdarozcelik@iyte.edu.tr, 902327507557.

Current address of K.Ocakoglu: Advanced Technologies Research \& Application Center, Mersin University, TR-33343 Yenisehir, Mersin, Turkey. 


\section{Introduction}

Fluorescent silica nanoparticles are one of the preferred materials for labeling in bioanalysis and biotechnological applications. Their silica shell shown to be biocompatible and non-toxic [1], protects fluoroscent dye molecules from the surrounding environment and encapsulates the dyes in its network [2], providing photostability and signal enhancement, respectively [3-12]. Moreover, easy surface modification of silica promotes conjugation of biomolecules such as proteins, peptides, antibodies, oligonucleotides, etc. [4, 5, 12-18]. In general, two methods have been used for the synthesis of silica-based nanoparticles: the reverse microemulsion [19-25] and the Stöber method [26]. These methods offer certain advantages with some limitations. For instance, in the reverse microemulsion method, excellent uniformity of the particles at the nanometer scale can be obtained and their surfaces are easily modified with functional groups including thiol, amine, and carboxylate during reaction [19-25]. On the other hand, dye molecules can be released from silica matrix because of the lack of the covalent attachment of a fluorophore to the silica matrix, leading decreased brightness $[\mathbf{2 7}, \mathbf{2 8}]$. In addition, this method requires large amount of surfactants and organic solvents. Alternatively, the method introduced by Stöber in 1968 [26] is usually the choice for the preparation of pure silica particles and hydrophobic organic dye-doped particles [29-33]. This method is comparatively simple, yet limited by the uniformity of particles, particularly those in the sub-50 $\mathrm{nm}$ range. Therefore, filtration and further separation techniques are usually applied to obtain particles with uniform size distribution. Additional silica coating (postcoating) with functional groups after particle synthesis is a way to modify surfaces of particles for specific applications.

Studies aiming of controlling particle size have been focussed on how nanoparticle synthesis is effected by the relative amounts of reagents used [16, 29-33, 39, 44, 47-52]; however, diverse results regarding to control size were reported in the literature of silica particles. Yokoi et al. introduced a novel method to prepare particles in the presence of octane, water, and basic amino acids instead of ammonia in weakly basic conditions ( $\mathrm{pH}$ of 9 - 10). This new method produced highly monodisperse particles in the size range of 12 to $23 \mathrm{~nm}[\mathbf{4 7}, \mathbf{4 8}]$. Recently, the formation mechanism of this new technique and the role of the amino acids, L-lysine and arginine were explained [49]. In a similar study, successful control of the size of particles was achieved by Hartlen et. al. by using arginine as the basic amino acid in the medium [52].

The integration of fluorescent molecules into silica particles have been well studied [2742]. Incorporating dyes into a silica matrix may be realized by covalent binding as well as via electrostatic interactions between the dye molecules and the silica matrix [43-44]. Van Blaaderen et al. introduced covalent binding of dye molecules into silica particles. Larson et al. synthesized particles with three different architectures possessing the same size, about $30 \mathrm{~nm}$. They demonstrated that the brightness of the particles increased due to enhanced radiative rate. The Weisner group successfully improved their method and achieved to prepare fluorescent particles with hydrodynamic diameter as small as $6.6 \mathrm{~nm}$ [45]. They showed that silica particles circulate in the mouse body upto six hours without the accumulation in organs such as liver and kindey. This study proves the possible utilization of silica nanoparticles for clinical applications. Ma et. al. investigated the effects of interactions between dye molecules for the particles in range from 15 
$\mathrm{nm}$ to $200 \mathrm{~nm}$ showed that the quantum yield of particles increased in the case of covalent bonding [46]. Hence, they recommend that dyes should be conjugated into a silica network by covalent bonding. Recently, $\mathrm{Ha}$ et. al. initiated a new coupling method [51]. In this method, the consecutive allylation and hydrosilation processes were applied to organic dyes to derivatize them. The new method aimed to eliminate the use of (3-aminopropyl) triethoxysilane (APTES) which otherwise cause agglomeration of particles. After modifying the structure of the dye molecules in two steps, the derivatives were conjugated into the silica matrix by the Stöber method. Additionally, they varied the size of particles from 30 to $500 \mathrm{~nm}$ by adjusting the concentration of TEOS, ammonia and water. Relatively longer processing and purification times after allylation require more reagents and a higher amount of dye may be considered as disadvantage for the method introduced by $\mathrm{Ha}$ et al.

Even though there are many reports regarding how to control the size and uniformity of nanoparticles. Some of the methods have been successful at producing particles bigger than 30 $\mathrm{nm}$ while others have focused on the preparation of particles smaller than $30 \mathrm{~nm}$. In addition, controversial results regarding the effect of amount of reagents on particle size were reported in the silica literature, although silica chemistry is well understood. Synthesis of particles by the Stöber method usually resulted in a polydispersed size distribution for the size less than $50 \mathrm{~nm}$. Therefore, a systematic study of controlling the solution chemistry is needed to explore how to control size and uniformity of particles. The aim of our study is systematically to control and tune the hydrodynamic size of fluorescent silica particles by varying the concentrations of the reagents and solvent.

Here we report a systematic method to produce uniform fluorescent particles by modifying the Stöber method. How relative amounts of reagent influence the particle size, monodispersity, and photophysical properties, are investigated here in details. We showed that the amount of ethanol and ammonia precisely tunes the size of silica nanoparticles. Lastly, we evaluated size dependent cytotoxicity of the fluorescent silica nanoparticles against cancer cell lines.

\section{Experimental}

Tetraethyl orthosilicate (TEOS) and fluorescein isothiocyanate (FITC, isomer I) were purchased from Fluka. 3-aminopropyl triethoxysilane (APTES, Alfa Aesar), $\mathrm{NH}_{4} \mathrm{OH}$ (ammonium hydroxide, 25 wt\%, Merck), ethanol (Riedel) were used as received. Deionized (DI) water was used throughout the study.

In a typical synthesis, APTES $(0.385 \mathrm{mmol})$ and FITC $(0.0135 \mathrm{mmol})$ were dissolved in 1.0 $\mathrm{ml}$ of absolute ethanol in the dark and stirred magnetically for about $18 \mathrm{~h}$ at room temperature under a nitrogen atmosphere. The stock solution of the APTES - FITC conjugate was kept in the dark to prevent photobleaching and later used as a fluorescent silane reagent for the production of the fluorescent part of the nanoparticles. To form a silica network around the APTES-FITC conjugate, appropriate amounts of ammonia, ethanol and TEOS given in Table 1 (22 independent batches) were mixed in a $100 \mathrm{ml}$ round-bottom flask with a magnetic stirring. Reaction times were kept constant for each experiment to prevent adventitious kinetic factors. The solution was allowed to stir for $24 \mathrm{~h}$. Lastly, $245 \mu$ TEOS was added as the post-coating step for particles and 
stirred for 24 hours more in the same reaction flask. This last step provides a facile means by which to modify the surface of particles via a rich library of silicates. The FITC-conjugated silica particles were washed four times with ethanol to remove unconjugated dyes and other reagents. The purified samples were then dried under nitrogen for physicochemical characterization.

The size and uniformity of the synthesized particles were measured by SEM (Scanning Electron Microscope, Phillips (FEI) XL30- SFEG) and DLS (Dynamic Light Scattering, Zetasizer $3000 \mathrm{HSA})$. Absorption and fluorescence spectra were recorded by Varian Cary 50 UV-Visible and Varian Eclipse fluorescence spectrophotometers, respectively. ${ }^{29} \mathrm{Si}$ NMR measurements were carried out on a Bruker Avance 500WB $99 \mathrm{MHz}$ NMR spectrometer. ${ }^{13} \mathrm{C}$-NMR experiments were performed with a Bruker $400 \mathrm{MHz}$ spectrometer.

Viability of cell lines of MCF7 and PC3 was evaluated by MTT assay. Particles with the size of 12,48 and $255 \mathrm{~nm}$ were dispersed in PBS with dosages up to $1000 \mu \mathrm{g} / \mathrm{mL}$. Incubation times were varied up to 72 hours.

\section{Results}

Silica particles at nanometer scales were prepared by a procedure based on a modified Stöber method as described in the experimental section. To tune and optimize particle size during preparation of each batch, the amount of one of the reagents was systematically adjusted while the amounts of the other reagents were kept constant; in total there were 22 independent batches. Table 1 summarizes the amounts of reagents, experimental conditions, and measurements of the hydrodynamic size of silica particles.

The first series of experiments (the set of Exp. No. 1) dealt with the amount of ammonia that was varied in range of 0.3 to $4.8 \mathrm{ml}(0.13-1.78 \mathrm{M})$. The hydrodynamic size of particles was determined DLS measurements confirming that particle size distributions were monodispersed (standart deviations given in Table 1). Figure 1 shows representative results of hydrodynamic size distributions of particles prepared under different set of conditions. The size and shape of particles were verified by SEM images as shown in Figure 2 illustrating that the particles were uniformly spherical.

Following evidence the particles were monodisperse, the relationship between the size and the initial amount of reagents were analyzed in details. A plot of particle size versus the volume of ammonia (Figure $3 \mathrm{~A}$ ) indicated two regions around a turning point of $1.2 \mathrm{ml}(0.49 \mathrm{M})$. The size of particles in both regions was linearly proportional to the amount of ammonia. For experiments where more than $1.2 \mathrm{ml}$ ammonia was used in the reaction, particle becomes larger as a function of initial volume of ammonia increased. This result suggests that silica particles in a desired size can be produced by simply adjusting the initial amount of ammonia within the conditions provided here. 
Table 1. Experimental conditions and results of DLS measurements - hydrodynamic diameter of particles measured under various experimental conditions.

\begin{tabular}{|c|c|c|c|c|c|c|c|c|}
\hline Exp. No. & & $L^{a}$ & & $2^{b}$ & & & & \\
\hline \multirow[t]{2}{*}{ Reagents } & \multicolumn{2}{|c|}{ Ammonia } & \multicolumn{2}{|c|}{ Ethanol } & \multicolumn{2}{|c|}{$\begin{array}{c}\text { TEOS } \\
\end{array}$} & \multicolumn{2}{|c|}{ APTS-FITC } \\
\hline & $\begin{array}{c}{\left[\mathbf{N H}_{3}\right]} \\
(\mathrm{M})\end{array}$ & $\begin{array}{c}D_{\text {DLS }} \\
(\mathrm{nm})\end{array}$ & $\begin{array}{c}\text { [EtOH] } \\
\text { (M) }\end{array}$ & $\begin{array}{c}D_{\text {DLS }} \\
(\mathrm{nm})\end{array}$ & $\begin{array}{c}\text { [TEOS] } \\
\text { (M) }\end{array}$ & $\begin{array}{c}D_{\text {DLS }} \\
(\mathrm{nm})\end{array}$ & $\begin{array}{l}\text { Vol. } \\
(\mathrm{ml})\end{array}$ & $\begin{array}{c}D_{\text {DLS }} \\
(\mathrm{nm})\end{array}$ \\
\hline A & 0.13 & $17 \pm 2$ & 11.4 & $465 \pm 109$ & 0.07 & $48 \pm 6$ & 0.060 & $32 \pm 4$ \\
\hline B & 0.25 & $27 \pm 6$ & 13.7 & $255 \pm 10$ & 0.14 & $46 \pm 7$ & 0.100 & $38 \pm 8$ \\
\hline C & 0.49 & $37 \pm 2$ & 14.7 & $105 \pm 29$ & 0.20 & $44 \pm 2$ & 0.160 & $22 \pm 4$ \\
\hline D & 0.95 & $181 \pm 50$ & 15.2 & $48 \pm 4$ & 0.27 & $31 \pm 6$ & 0.320 & $28 \pm 9$ \\
\hline $\begin{array}{l}\mathbf{E} \\
\mathbf{F}\end{array}$ & 1.78 & $445 \pm 76$ & $\begin{array}{l}15.8 \\
16.1\end{array}$ & $\begin{array}{l}31 \pm 2 \\
12 \pm 4\end{array}$ & $\begin{array}{l}0.33 \\
0.39\end{array}$ & $\begin{array}{l}27 \pm 9 \\
26 \pm 7\end{array}$ & 0.640 & $36 \pm 10$ \\
\hline
\end{tabular}

The experiments were performed at room temperature in the presence of

${ }^{a} 0.1 \mathrm{ml}$ APTES-FITC, $1.2 \mathrm{ml}$ TEOS, $30 \mathrm{ml}$ ethanol and $0.3-4.8 \mathrm{ml}$ ammonia.

${ }^{b} 0.1 \mathrm{ml}$ APTES-FITC, $1.2 \mathrm{ml}$ ammonia, $1.2 \mathrm{ml}$ TEOS, and $5.0-60 \mathrm{ml}$ ethanol.

${ }^{c} 0.1 \mathrm{ml}$ APTES-FITC, $1.2 \mathrm{ml}$ ammonia, $30 \mathrm{ml}$ ethanol, and $0.5-3.0 \mathrm{ml}$ TEOS.

${ }^{d} 1.2 \mathrm{ml}$ ammonia, $1.2 \mathrm{ml}$ TEOS, $30 \mathrm{ml}$ ethanol.

Standart deviations were determined from the size distributions.

All reactions including the synthesis of the fluorescent conjugate and formation of the silica network were performed in the presence of ethanol. Therefore, ethanol is the solvent of the reaction medium in this work. The amount of ethanol was adjusted from 60.0 to $5.0 \mathrm{ml}$ (Table 1, the set of Exp. No. 2). Ethanol produced during the hydrolysis of TEOS was not taking into account since a constant amount of TEOS was used in the set of Exp. No. 2. The effect of the amount of ethanol on the size of the particles is presented in Figure 3B. The adjustment of the volume of ethanol yields highly uniform nanoparticles in the size range from $12 \mathrm{~nm}$ to $465 \mathrm{~nm}$. As shown in Figure 3B, there is an exponential dependence of the particle size to the initial volume of ethanol. The exponential dependence indicates that the initial amount of ethanol is the major factor regulating the particle size.

After determining how amounts of ammonia and ethanol tune the size of particles, the effect of the amount of TEOS on the size was studied. The amount of TEOS was increased from 0.5 $\mathrm{ml}$ to $3.0 \mathrm{ml}$ (Table 1, the set of Exp. No. 3). Figure 3C shows that amounts of TEOS up to $1.5 \mathrm{~mL}$ were not effective the within experimental error on the particle size (about $45 \mathrm{~nm}$ ), however, when the amount of TEOS was higher than $1.5 \mathrm{~mL}$ the particle size was meaningfully reduced to $25 \mathrm{~nm}$. The change in particle size was not proportional to the amount of TEOS in the reaction flask although the amount of TEOS increased by a factor of six. Thus, the variation in the amount of TEOS does not greatly affect the particle size in the concentration range used in this study, as compared to the profound effects of the amount of ammonia and ethanol.

We next investigated the amount of APTES-FITC conjugate on particle size (Table 1, the set of Exp. No. 4). DLS results showed that particle size varied with increasing amounts of APTESFITC (Table 1). There was a fluctuation in size when a lower amount of APTES-FITC conjugate (less than $0.1 \mathrm{~mL}$ ) was employed. The particle size was increased in a linear fashion as the amount of the conjugate was increased as shown Figure 3D. The effect of the amount of conjugate on particle size is determined to be not substantial. 
Under these experimental conditions, the results point out that the amount of ammonia and ethanol are very effective to tune the hydrodynamic size of particles. The two other reagents TEOS and APTES-FITC conjugate played a limited role on the size and monodispersity of particles under the experimental conditions presented here.

${ }^{13} \mathrm{C}$ and ${ }^{29} \mathrm{Si}$ CP-MAS NMR spectroscopy are powerful methods for characterizing the chemical structure of substances that can be prepared from (organo)-alkoxysilanes [31, 53]. Using these methods, it is also possible to obtain information about the surface characteristics of silica particles such as type and amount of coverage and number of the bonds that have been formed in the coating reactions. ${ }^{29} \mathrm{Si}$ CP-MAS NMR spectra revealed well-defined broad lines, as expected, at $-111.4\left(\mathrm{Q}^{4}\right),-101.5\left(\mathrm{Q}^{3}\right)$ and $-92.7\left(\mathrm{Q}^{2}\right) \mathrm{ppm}$ (Figure $\left.4 \mathrm{~A}\right)$. It is easy to distinguish between the $\mathrm{Q}^{4}, \mathrm{Q}^{3}$, and $\mathrm{Q}^{2}$ silicons, because their chemical shifts are all separated by approximately $10 \mathrm{ppm}$. The existence of an Si-C bond causes a shift at approximately $45 \mathrm{ppm}$ and again there is a separation of about $10 \mathrm{ppm}$ between the the $\mathrm{T}^{3}, \mathrm{~T}^{2}$, and $\mathrm{T}^{1}$ silicons [31]

However, such formations were not observed except a tiny peak at $-67.4 \mathrm{ppm}$ that can be ascribed to $\mathrm{T}^{3}$ silicons. ${ }^{13} \mathrm{C}$ CP-MAS NMR measurements were used to qualitatively characterize the fate of the ethoxy and aminopropyl groups of the (organo)-alkoxysilanes on the particle surface (Figure 4B). Two major ${ }^{13} \mathrm{C}-\mathrm{NMR}$ signals were observed at 17.7 and $59.1 \mathrm{ppm}$ that were attributed to the equivalent carbons of the $-\mathrm{CH}_{3}$ and $-\mathrm{O}-\mathrm{CH}_{2}$ - of TEOS, respectively. However, the formation of small peaks at $10.0\left(\mathrm{Si}-\mathrm{CH}_{2}\right), 23.5\left(-\mathrm{CH}_{2}-\mathrm{CH}_{2}-\mathrm{CH}_{2}-\right)$ and $43.1 \mathrm{ppm}\left(-\mathrm{CH}_{2}-\mathrm{NH}_{2}\right)$ can be ascribed to APTES (Figure 4B). These spectra are considered as proof of the existence of $-\mathrm{NH}_{2}$ groups in the particle structure, although an additional amount of TEOS was used at the post coating step. Overall, NMR measurements along with microscopic and scattering measurements identified the formation of siloxane bonds and silica particle formation.

It is important to control the number of FITC molecules conjugated to silica particles. To determine the amount of conjugated FITC, the silica particles were intentionally disintegrated in a $1 \mathrm{M}$ aqueous solution of $\mathrm{NaOH}$. Figure 5 shows the absorption and fluorescence spectra of FITC released as a result of the degradation of silica particles prepared in the set of Exp. No. 1. Figure $5 \mathrm{~A}$ shows an increase in absorbance as the particle size was increased. The released number of FITC molecules was determined by absorbance measurements of the supernatant obtained as a result of the disintegration of silica particles. The amount of FITC released into the solution was determined to be from $0.02 \mu \mathrm{M}$ for the smallest particle to $1.40 \mu \mathrm{M}$ for the largest one. This indicates that the number of FITC molecules disintegrated from the particles increased as the particles become larger, with supporting evidence being that the larger particles contained a higher number of FITC molecules. Similarly Figure 5B demonstrates that the intensity of fluorescence was amplified for larger particles. These results verify that there is a linear relationship between the number of FITC molecules conjugated to particles and particle size. The results lead us to conclude that the density of the FITC molecules per particle is equivalent. The same results (Figures 5C and 5D) were observed when the size of the particles varied as a function of the amount of ethanol (the set of Exp. No. 2); there is an exponential trend. Figure 6, a 3D-plot, reveals the relationships among size, absorbance, and fluorescence intensity.

To confirm whether the silica network protects dye molecules, the particles were treated with environmental factors such as solvents, $\mathrm{pH}$ and quenchers. The fluorescence spectra of FITC 
molecules both dissolved in and conjugated to the silica particles dispersed in dimethyl formamide, ethanol, and water are presented in Figure 7. The shape of the fluorescence spectra of FITC dissolved in the solvents changed, and the peak position shifted to red due to the solvatochromatic effect (increased orientational polarizability) as the solvent molecules interact freely with FITC molecules. However, the spectra of FITC conjugated to the particles (Figure 7B) showed no variation with the solvents. Apparently the solvent molecules do not reach the FITC molecules conjugated to the particle; an effective protection layer against solvents has been provided by the silica network for FITC molecules.

Fluorescence quenching is a process causing a reduction in the fluorescence intensity of a fluorophore if a quencher interacts with the fluorophore. Accordingly, quenching studies can be used to reveal the interaction of a quencher with dye molecules conjugated to silica. We performed fluorescence quenching studies by using $\mathrm{CuCl}_{2}$ and $\mathrm{KI}$ as quenchers to assess the protection ability of the silica network for dye molecules against the quenchers. The fluorescence spectra of FITC conjugated-silica particles with the size of 30 and $180 \mathrm{~nm}$ dispersed in aqueous solutions were recorded. The Stern-Volmer plots were obtained for the assessment of quenching. For comparison, the aqueous solutions of FITC were also prepared and its fluorescence monitored by increasing the amounts of the quenchers. Figure 8 depicts The Stern-Volmer plots showing that quenching of FITC in aqueous solutions by $\mathrm{Cu}^{2+}$ and $\mathrm{I}^{-}$ions is strong, but the FITC conjugated to the particles is weakly affected by the quenchers depending on its type and amount. When the $\left[\mathrm{Cu}^{2+}\right]$ is higher than $0.1 \mathrm{M}$, a precipitation was observed, limiting the quenching study for higher concentrations. On the other hand, the negatively charged quencher $\mathrm{I}^{-}$interacts with FITC conjugated to particles and the fluorescence intensity was quenched in to a certain extent,

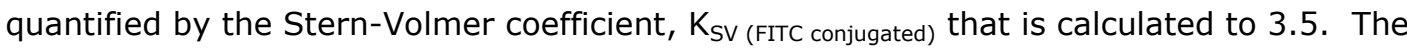
quenching of FITC in aqueous solution was substantial and was quantified by the coefficient $\mathrm{K}_{\mathrm{sV}}$ (FITC-free) to be equal to 15.1. By comparing the SV coefficients, we see that FITC molecules easily interact with quenchers in aqueous solution. The silica network provides a certain level of protection for FITC-conjugated to the particles. It indicates that the quencher ions are able to penetrate into the silica network and interact with some of the FITC molecules presumably close to the surface of the particles. Diffusion ability of the quenchers to the conjugated FITC indicates that the silica particles may possess an open structure or surfaces that allow ions to diffuse the silica network.

It is well known that $\mathrm{pH}$ of environment through protonation of FITC modulates fluorescence intensity and therefore the fluorescence of FITC is sensitive to solution $\mathrm{pH}$ of its environment. Therefore, investigating the influence of $\mathrm{pH}$ on FITC conjugated to particles could further demonstrate the protective nature of the silica matrix. The $\mathrm{pH}$ of the aqueous solution was adjusted from 6 to 13. Figure 9 represents how the $\mathrm{pH}$ of the solution makes an impact on the fluorescence spectra of FITC in solution or conjugated to silica particles. Reduction in the fluorescence intensity was observed for FITC when dissolved in aqueous solution, but the intensity of the FITC-conjugated to particles remained almost unchanged. There was a $30 \%$ decrease in intensity for $\mathrm{pH}$ higher than 11 that indicates the disintegration of the particles. The spectral shape and position also did not change with $\mathrm{pH}$. These findings confirmed the protection provided by the silica matrix to FITC against changes in $\mathrm{pH}$ of the environment. 
Photostability performance of the particles was checked by photobleaching of FITC emission. The test was applied to particles containing different amounts of dye molecules (Table 1, Exp. No. 4). Variation in the fluorescence intensity of the particles with time was monitored up to 100 min under continuous illumination. It was observed that the fluorescence intensity reduced rapidly within 5 minutes and remained unchanged after 20 minutes as seen in Figure 10 . The fluorescence intensity of the larger particles containing higher amounts of APTES-FITC conjugate was determined to be decreased by $3 \%$ and $13 \%$ at 5 and $100 \mathrm{~min}$, respectively. The intensity was decreased by $5 \%$ at $5 \mathrm{~min}$., and by $21 \%$ at $100 \mathrm{~min}$. for the smaller particles. The rate of photobleaching was greater for the particles containing a lower number of dye molecules. These measurements illustrated that particles encapsulating a higher number of FITC molecules are much brighter for a prolonged period of time.

Assessment of cell viability is important for the biological and medical applications of silica particles. Figure 11 shows the results of size dependent cell viability determined by the MTT assay for MCF7 and PC3 cells. Cells were incubated with the particles (size of 12 to $255 \mathrm{~nm}$ ) at dosages up to $1000.0 \mu \mathrm{g} / \mathrm{mL}$. Incubation times up to 72 hours were employed. Under these experimental conditions cell viability of MCF7 and PC3 cells with respect to particle size, dosage, and incubation time remained unchanged. The results point out no size dependent cytotoxicity. Silica particles do not stimulate cell death on MCF7 and PC3 cell lines.

\section{Discussion}

The discussion section is mainly devoted to particle formation. Hydrolysis and condensation of silicates leads to the formation of silica particles. Concurrently, solution chemistry is important for the formation of these particles. In this work, based on a modified Stöber method, the initial amounts of reagents were systematically varied to better elucidate the role of each reagent on the hydrodynamic size of fluorescent silica nanoparticles.

The formation of silanols [ $(\mathrm{EtO})_{3} \mathrm{SiOH}$ and $\left.(\mathrm{EtO})_{2} \mathrm{Si}(\mathrm{OH})_{2}\right]$ as key intermediates during TEOS polymerization is well known. Condensation of silanol, $\equiv \mathrm{Si}-\mathrm{O}-\mathrm{H}$, as an intermediate via an $\mathrm{SN}_{2}$ mechanism, yields the siloxane bonds, $\equiv \mathrm{Si}-\mathrm{O}-\mathrm{Si} \equiv$. Under base-catalyed conditions there is an equilibrium between the hydroxide and ethoxide nucleophiles because of the similar pKa values of their conjugate acids. Nucleophilic attack of the ethoxide ion to a silicon center of TEOS will not yield formation of any product (the Scheme A). On the other hand, nucleophilic attack of a hydroxide ion to the silicon center will produce a silanol structure which is more acidic than ethanol. A Bronsted acid-base reaction will form a nucleophilic silyloxide, which will react further with a second TEOS molecule to form $\mathrm{a} \equiv \mathrm{Si}-\mathrm{O}-\mathrm{S} \mathrm{S} \equiv$ bond (the Scheme $\mathrm{A}$ ). An increase in the concentration of ethanol may shift the equilibrium to the right thus increasing the concentration of ethoxide ions and decreasing the concentration of hydroxide ions. Such control over the hydroxide ion concentration plays a key role in the nucleation and growth and therefore the size of the silica nanoparticles.

As explained in the Scheme A the concentration of ethanol in the reaction medium is critical to the formation of siloxane bonds. We found that the size of particles exponentially decreased with increasing initial amount of ethanol (11-16 $\mathrm{M}$ in the presence of $0.49 \mathrm{M}$ ammonia) as shown in Figure 3B. Higher amounts of hydroxide ions are available when lower volumes of ethanol are 
used thus yielding more interactions between the initial nucleate and hydrolyzed monomer. On the other hand, the number of interactions decreases with the increasing amount of ethanol. Ethanol and methanol as solvent were used in some studies [30,56,57]. Smaller particles were formed in methanol as compared to ethanol. However, in the literature neither ethanol nor methanol has been progressively varied to comprehend the effect of solvent on the size of silica particles. In one particular study, Rao et al. showed that ethanol in the range of 4-10 M (in 3 different batches) yielded an increase for the size of particles in the presence of $14 \mathrm{M}$ ammonia. The increase in particle size may be attributed to the presence of a very high concentration of ammonia, producing an excess amount of hydroxide ions in the reaction medium. There is a consensus in the literature that a progressive increase in the amount of water yields formation of larger silica nanoparticles. We verified the effect of increased amounts of water on the size of particles.

Scheme A: Formation of silanol and siloxane bonds

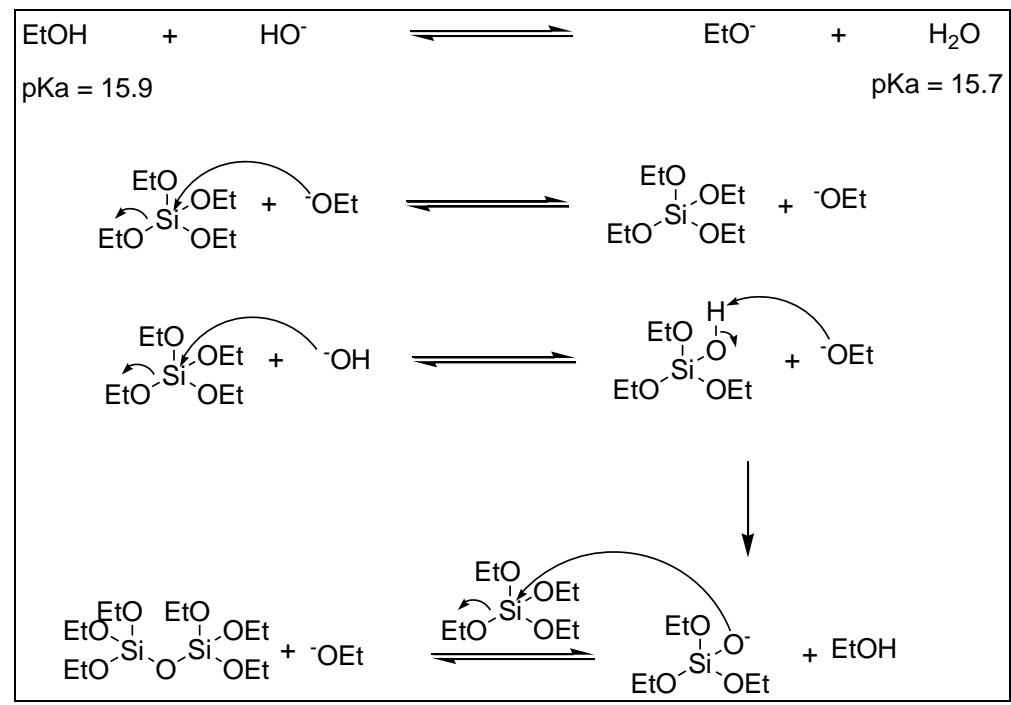

Amount of ammonia strongly controls the particle size and our results agrees very well with the literature. Ammonia served as a reactant and a catalyst for the hydrolysis of TEOS. One of the reactant $\mathrm{OH}^{-}$ions provided by ammonia is important for the formation of particles. The literature shows that the concentration of the basic catalyst is responsible to tune particle size [39, 44, 47$\mathbf{5 1}, \mathbf{5 6}, \mathbf{5 7}, \mathbf{6 2}]$. In our study, we systematically varied the amount of ammonia from $0.13 \mathrm{M}$ to $1.78 \mathrm{M}$ and showed that the size of the particles increased as the amount of ammonia was raised. The reports regarding the effects of ammonia on the size of particle are controversial. Rao et. al. observed that the size of particle decreased with increasing the ammonia concentration (2.80 28.0 M) in the presence of $1.0-8.0 \mathrm{M}$ ethanol and 3.0-14.0 $\mathrm{M}$ water [62]. On the other hand, Bagwe et. al. showed that the increase in the amount of ammonia $(0.16-0.64 \mathrm{M})$ yielded larger particles [50]. In addition to these, Ha et. al. reported that the greater the amount of ammonia the larger the particle size [51], but they concurrently increased the amount of water (2.0-7.8 M) and the reaction time. Furthermore, Wiesner and Ow showed that larger particles (100-500 nm) 
were obtained in the presence of higher amounts of ammonia (3.4-6.1 M) and water (10.8- 16.8 M), while particles smaller than $100 \mathrm{~nm}$ were prepared with lowered amount of ammonia (0.2$0.0085 \mathrm{M}$ ) [63]. Tan et. al. controlled the size of particles and demonstrated the particle size was decreased from $70 \mathrm{~nm}$ to $25 \mathrm{~nm}$ when the amount of ammonia was reduced three-fold of its initial value $[\mathbf{1 0}, \mathbf{1 1}]$. These reports clearly point out that the solution chemistry is detrimental to tune the size of particle. A systematic investigation to generate a set of data regarding the effect of the amounts of reagents on the size of particles is essential. However, each report used different set of experimental conditions and the concentration of reagents was not systematically varied. Our study clears the inconsistency among the results reported in the literature.

The influence of the amount of TEOS on particle size is limited in our study (16 M ethanol, $0.49 \mathrm{M}$ ammonia). Many studies in the literature again are controversial. Tunability on the particle size as a function of the increased concentration of TEOS has been studied [49 - 51, 60-62]. Bagwe et. al. reported that there was no change in particle size when they increased the concentration of TEOS from 0.025 to $0.1 \mathrm{mM}$ [50]. Rao et. al. found that as the concentration of TEOS was increased from 0.012 to $0.12 \mathrm{M}$, increase in particle size from 60 to $417 \mathrm{~nm}$ were obtained in the presence of $8 \mathrm{M}$ ethanol, $3 \mathrm{M}$ water, and $14 \mathrm{M}$ ammonia [62]. Yokoi et. al. reported that TEOS increased particle size by three fold $(\sim 12-36 \mathrm{~nm})$ although the amount of TEOS was increased by twelve-fold (from 1 to $12 \mathrm{M}$ ) [36]. It is well known that four moles of ethanol are produced for each mol of TEOS during the hydrolysis and condensation reactions. Thus, the initial amount of TEOS contributes to the total amount of ethanol in the reaction medium. We already stated that the amount of ethanol is the most important parameter to control the size of particles. Increase in the amount of hydrolyzed ethanol may cause a reduction in the size of the particle as the concentration of TEOS increased. This is exactly what we observed.

As expected, the amount of APTES - FITC conjugates did not have an impact on particle size. Imhof et. al. investigated the effect of APTES-FITC conjugate amount by varying the conjugate concentration between 10 and $640 \mu \mathrm{l}$ [39]. In their experiments the conjugate was steadily increased, as a result particle size increased slightly from 200 to $250 \mathrm{~nm}$. They obtained their largest particles when the amount of the FITC conjugate was increased from 320 to $640 \mu$ in different volumes of ethanol. Our work validates the particle size is not greatly affected by amount of the FITC-conjugate. But, silica particles are much smaller under the experimental conditions presented when the fluorescent conjugate was not added during the synthesis. The separate set of experiments in the absence of the fluorescent conjugate summarized in the supporting information.

Many biological applications rely on fluorescence properties such as intensity and emission wavelength and thus it is desirable to have fluorescent particles with spectral features that remain unaffected by the environmental factors. Solvent, $\mathrm{pH}$, and ions in solutions or cellular environment may change spectral properties of fluorescent particles if the fluorophore that is conjugated to silica is accessible to the environment. We show that the silica network keeps the spectral properties of FITC unaffected against the $\mathrm{pH}$ of the solution and the solvent. This is imperative for biological applications such as tracking the motions of proteins and the locations of drug carriers. Such applications depend on stable fluorescent intensity because the motions and locations of proteins and DNAs may be probed by a fluorescent molecule or a single fluorescent particle. Fluorescent silica particles may contain many fluorophores; therefore, the particles may emit for a longer 
period of time, allowing an extended period of observation. Only a limited number of fluorescent probes may present such stability. Many probes report fluctuations and variations of their environment.

Biocompatible, biodegradable and non-toxic materials are required for biological and medical applications. Silica is shown to possess these features and, as a result, it is a biomaterial of choice. To this end, we demonstrated that the fluorescent silica particles produced in this work are not toxic against cancer cells MCF7 and PC3. Many studies agree that silica is not toxic at all and safe for use in biological applications. For medical application, it is crucial that the hydrodynamic diameter of silica nanoparticles must be smaller than $7.0 \mathrm{~nm}$ to be cleared out from body [45]. This indicates that the hydrodynamic size of silica must be reduced for clinical applications such as the safe delivery of drugs to organs and tissues. This fact requires more systematic work to figure out how to reduce the hydrodynamic size of silica particles, albeit one study already has been reported by the Weisner group [45]. It is reported that silica particles are approved by FDA for the first clinical trials. Surface potential, basicity, and acidity of silica surfaces are important factors to elucidate the fate of the silica particle for biological and medical applications. We will direct our attention to these areas and extend our work to determine the locations and motions of fluorescent silica particles in normal and cancerous cell lines as a function of surface chemistry and surface potentials.

\section{Conclusions}

We present a method to systematically synthesize monodispersed FITC conjugated silica particles by using a modified Stöber method. The hydrodynamic size of fluorescent particles was tuned in the range from 12 to $465 \mathrm{~nm}$. We demonstrated that the systematic control of hydrodynamic size of particles can be achieved by regulating the solution chemistry. We showed that the size strongly depends upon the amount of ethanol and ammonia. Higher amount of ethanol regulated the concentration of hydroxide ion leading to controlled-growth of the silica particles and resulting in precisely tuning the hydrodynamic size. Moreover, we showed that the amount of dye conjugated to the particles can be controlled by the size of the particles. The concentration of FITC molecules conjugated to particles was varied between 0.02 to $1.40 \mu \mathrm{M}$. The silica network protects FITC molecules against $\mathrm{pH}$, solvent, and partially to ionic quenchers in a limited extent. Penetration ability of ionic quenchers may be interpreted that silica particles may have open structure in the sub-nanometer scale on the surface of the particles because solvent molecules do not reach conjugated FITC molecules to induce solvent effects. We propose that fluorescent silica nanoparticles may possess an open structure on the surface of the particles and may not have a fluorescent core/silica shell structure as assumed in the literature. Furthermore, the silica particles are not cytotoxic up to $1.0 \mathrm{mg} / \mathrm{mL}$ and up to 72 hours of incubation period, respectively. The particles may be ready for biological applications, but they are not ready for medical applications without evidence of their clearance from the body. Moreover, other biological functions such as inflammation and genotoxicity must be studied because the biological response of cells is not limited to cytotoxicity. 
Acknowledgements: This work was partially supported by TUBITAK (project number of 108T446) and DPT (the State Planning Organization of Turkey). We thank Muhsin Ciftcioglu and Ali Cagir for fruitful discussions and Ritchie Eanes for proofreading of the manuscript. We acknowledge that part of studies was carried out at IYTE-MRC and IYTE-Biyomer. 


\section{References}

1. Rosi, N. L.; Mirkin, C. A. Nanostructures in biodiagnostics. Chem. Rev. 2005, 105, 1547.

2. Zhao, X. J.; Bagwe, R. P.; Tan, W. H. Development of organic-dye-doped silica nanoparticles in a reverse microemulsion. Adv. Mater. 2004, 16, 173.

3. Bringley, J. F.; Penner, T. L.; Wang, R.; Harder, J. F.; Harrison, W. J.; Buonemani, L. Silica nanoparticles encapsulating near-infrared emissive cyanine dyes. J. Colloid Interf. Sci. 2008, 320, 132.

4. Santra S.; Zhang P.; Wang K. M.; Tapec R.; Tan W. H. Conjugation of biomolecules with luminophore-doped silica nanoparticles for photostable biomarkers. Anal. Chem. 2001, 73, 4988.

5. Santra S.; Wang K. M.; Tapec R.; Tan W. H. Development of novel dye-doped silica nanoparticles for biomarker application. J. Biomed. Opt. 2001, 6, 160.

6. Santra, S.; Liesenfeld, B.; Bertolinoa, C.; Dutta, D.; Caoc, Z. H.; Tan, W. H.; Moudgil, B. M.; Mericle, R. A. Journal of Luminescence 2006, 117, 75.

7. Santra, S.; Yang H.; Dutta, D.; Stanley, J. T.; Holloway, P. H.; Tan, W. H.; Moudgilb, B. M.; Mericle, R. A. TAT conjugated, FITC doped silica nanoparticles for bioimaging applications. Chem. Commun. 2004, 24, 2810.

8. Lian, W.; Litherland, S.A.; Badrane, H.; Tan, W. H.; Wu, D. H.; Baker, H. V.; Gulig, P. A.; Lime, D. V.; Jin, S. G. Ultrasensitive detection of biomolecules with fluorescent dye-doped nanoparticles. Anal. Biochem. 2004, 334, 135.

9. Yang, W.; Zhang, C. G.; Qu, H. Y.; Yang, H. H.; Xu, J. G. Novel fluorescent silica nanoparticle probe for ultrasensitive immunoassays. Anal. Chim. Acta 2004, 503, 163.

10. Wang, L.; Yang, C.; Tan, W. Dual-Luminophore-Doped Silica Nanoparticles for Multiplexed Signaling. Nano Letters 2005; 5, 37.

11. Wang, L.; Tan, W. Multicolor FRET Silica Nanoparticles by Single Wavelength Excitation. Nano Letters 2006, 6, 84.

12. Bagwe P. R.; Hillard L. R.; Tan, W. Surface Modification of Silica Nanoparticles to Reduce Aggregation and Nonspecific Binding. Langmuir 2006, 22, 4357.

13. Gao, F.; Luo, F. B.; Yin, J.; Wang, L. Preparation of aminated core-shell fluorescent nanoparticles and their application to the synchronous fluorescence determination of gammaglobulin. Luminescence 2008, 23, 392.

14. Hun, X.; Zhang, Z. J. Functionalized fluorescent core-shell nanoparticles used as a fluorescent labels in fluoroimmunoassay for IL-6. Biosensors \& Bioelectronics 2007, 22, 2743.

15. Shi, H.; He, X.; Wang, K.; Yuan, Y.; Deng, K.; Chen, J.; Tan, W. Rhodamine B isothiocyanate doped silica-coated fluorescent nanoparticles (RBITC-DSFParticles)-based bioprobes conjugated to Annexin $\mathrm{V}$ for apoptosis detection and imaging. Nanomedicine-Nanotechnology, Biology and Medicine 2007, 3, 266.

16. Roy, I.; Ohulchanskyy, T. Y.; Bharali, D. J.; Pudavar, H. E.; Mistretta R. A.; Kaur, N.; Prassad, P. N. Optical tracking of organically modified silica nanoparticles as DNA carriers: A nonviral, nanomedicine approach for gene delivery. Proceedings of the National Academy of Sciences of the United States of America 2005, 102, 279. 
17. Fuller, E. J.; Zugates, G.T.; Ferreira, L. S.; Ow, H. S.; Nguyen, N. N.; Wiesner, U. B.; Langer, R. S. Intracellular delivery of core-shell fluorescent silica nanoparticles. Biomaterials 2008, 29, 1526.

18. Qhobosheane, M.; Santra, S.; Zhang, P.; Tan, W. H. Biochemically functionalized silica nanoparticles. Analyst 2001, 126, 1274.

19. Yamauchi, H.; Ishikawa, T.; Kondo, S. Surface characterization of ultramicro spherical-particles of siliva prepared by w/o microemulsion method. J. Colloids Surf. 1989, 37, 71.

20. Osseoasare, K.; Arriagada, F. J. Preparation of $\mathrm{SiO} 2$ nanoparticles in a nonionic reserve micellar system. J. Colloids Surf. 1990, 50, 321.

21. Lindberg, R.; Sjöblom, J.; Sundholm, G. Preparation of silica particles utilizing the sol-gel and the emulsion-gel processes. Colloid Surface A 1995, 99, 79.

22. Arriagada F. J.; Osseoasare K. Synthesis of nanosize silica in aerosol OT reverse microemulsions. J Colloid Interface Sci. 1995, 170, 8.

23. Arriagada, F. J.; Osseoasare, K. Silica nanoparticles produced in aerosol OT reverse microemulsions-effect of benzyl alcohol on particle-size and polydispersity. J Disper. Sci Technol. 1994, 15, 59.

24. Arriagada F. J.; Osseoasare K. Phase and dispersion stability effects in the synthesis of silica nanoparticles in a nonionic reverse microemulsion. Colloids Surf. 1992, 69, 105.

25. Arriagada F. J.; Osseo-Asare K. Synthesis of nanosize silica in a nonionic water-in-oil microemulsion: Effects of the water/surfactant molar ratio and ammonia concentration. $J$ Colloid Interface Sci. 1999, 211, 210.

26. Stöber, W.; Fink, A.; Bohn, E. Controlled growth of monodisperse silica spheres in the micron size range. J Colloid Interface Sci. 1968, 26, 62.

27. Burns, A.; Ow, H.; Wiesner, U. Fluorescent core-shell silica nanoparticles: towards "Lab on a Particle" architectures for nanobiotechnology. Chemical Society Reviews 2006, 35, 1028.

28. Sharma, P.; Brown, S.; Walter, G.; Santra, S.; Moudgil, B. Nanoparticles for bioimaging. Adv. in Colloid Interfac. 2006, 123, 471.

29. Van Blaaderen, A.; Imhof, A.; Hage, W.; Vrij A. Three-dimensional imaging of submicrometer colloidal particles in concentrated suspensions using confocal scanning laser microscopy. Langmuir $1992,8,1514$.

30. Van Blaaderen, A.; Vrij, A. Synthesis and characterization of colloidal dispersions of fluorescent, monodisperse silica spheres. Langmuir 1992, 8, 2921.

31. Van Blaaderen, A.; Vrij, A. Synthesis and characterization of monodisperse colloidal organosilica spheres. J. Colloid. Interf. Sci. 1993, 156, 1.

32. Van Blaaderen, A.; Peetermans, J.; Maret, G.; Dhont, J. K. G. Long-time self-diffusion of spherical colloidal particles measured with fluorescence recovery after photobleaching. J. Chem. Phys. 1992, 96, 4591.

33. Nyffenegger, R.; Quellet, C.; Ricka J. Synthesis of fluorescent, monodisperse, colloidal silica particles. J. Colloid Interface Sci. 1993, 159, 150.

34. Burns, A.; Ow, H.; Wiesner, U. Fluorescent core-shell silica nanoparticles: towards "Lab on a Particle" architectures for nanobiotechnology. Chemical Society Reviews 2006, 35, 1028. 
35. Tapec R.; Zhao, X. J. J.; Tan, W. H. Development of organic dye-doped silica nanoparticles for bioanalysis and biosensors. J. Nanosci. Nanotechno. 2002, 2, 405.

36. Wang, L.; Wang, K. M.; Santra, S.; Zhao, X. J.; Hilliard, L. R.; Smith, J. E.; Wu, J. R.; Tan, W. H. Watching silica nanoparticles glow in the biological world. Analytical Chem. 2006, 78, 646.

37. Lettinga, M. P.; van Zandvoort, M. A. M. J.; van Kats, C. M.; Philipse, A. P. Phosphorescent colloidal silica spheres as tracers for rotational diffusion studies. Langmuir 2000, 16, 6156.

38. Verhaegh, N. A. M.; van Blaaderen, A. Dispersions of rhodamine-labeled silica spheressynthesis, characterization, and fluorescence confocal scanning laser microscopy. Langmuir 1994, $10,1427$.

39. Imhof, A.; Megens, M.; Engelberts, J. J.; de Lang, D. T. N.; Sprik, R.; Vos, W. L. Spectroscopy of fluorescein (FITC) dyed colloidal silica spheres. J.Phys. Chem. B 1999, 103, 1408.

40. Makarova, O. V.; Ostafin, A. E.; Miyoshi, H.; Norris, J. R.; Meisel, D. Adsorption and encapsulation of fluorescent probes in nanoparticles. J. Phys. Chem. B 1999, 103, 9080.

41. Dewar, P. J.; MacGillivray, T. F.; Crispo, S. M.; Smith-Palmer, T. Interactions of pyrene-labeled silica particles. J. Colloid Interface Sci. 2000, 228, 253.

42. Bele, M.; Siiman, O.; Matijevic, E. Preparation and flow cytometry of uniform silica-fluorescent dye microspheres. J. Colloid Interface Sci. 2002, 254, 274.

43. Larson, D. R.; Ow, H.; Vishwasrao, H. D.; Heikal, A. A.; Wiesner, U.; Webb, W. W. Silica nanoparticle architecture determines radiative properties of conjugated fluorophores. Chem. Mater. 2008, 20, 2677.

44. Ow, H.; Larson, D. R.; Srivastava, M.; Baird, B. A.; Webb, W. W.; Wiesner, U. Bright and stable core-shell fluorescent silica nanoparticles. Nano Lett. 2005, 5, 113.

45. Burns, A. A.; Vider, J.; Ow, H.; Herz, E.; Penate-Medina, O.; Baumgart, M.; Larson, S. M.; Wiesner, U.; Bradbury, M. Fluorescent Silica Nanoparticles with Efficient Urinary Excretion for Nanomedicine. Nano Lett. 2009, 9, 442.

46. Ma, D.; Kell, A. J.; Tan, S.; Jakubek, Z. J.; Simard, B. Photophysical Properties of Dye-Doped Silica Nanoparticles Bearing Different Types of Dye-Silica Interactions. J.Phys. Chem. C 2009, 113, 15974.

47. Yokoi, T.; Sakamoto, Y.; Terasaki, O.; Kubota, Y.; Okubo, T.; Tatsumi, T. Periodic arrangement of silica nanospheres assisted by amino acids. J. Am. Chem. Soc. 2006, 128, 13664.

48. Yokoi, T.; Iwama, M.; Watanabe, R.; Sakamoto, Y.; Terasaki, O.; Kubota, Y.; Kondo, J. N.; Okubo, T.; Tatsumi, T. Synthesis of well-ordered nanospheres with uniform mesopores assisted by basic amino acids. Stud. Surf. Sci. Catal. 2007, 170, 1774.

49. Yokoi, T.; Wakabayashi, J.; Otsuka, Y.; Fan, W.; Iwama, M.; Watanabe, R.; Aramaki, K.; Shimojima, A.; Tatsumi, T.; Okubo, T. Mechanism of Formation of Uniform-Sized Silica Nanospheres Catalyzed by Basic Amino Acids. Chem. Mater. 2009, 21, 3719.

50. Bagwe, R. P.; Yang, C.; Hillard, L. R.; Tan, W. Optimization of Dye-Doped Silica Nanoparticles Prepared Using a Reverse Microemulsion Method. Langmuir, 2004, 20, 8336.

51. Ha, S. W.; Camalier, C. E.; Beck, G. R.; Lee, J. K. New method to prepare very stable and biocompatible fluorescent silica nanoparticles. Chem. Commun., 2009, 20, 2881. 
52. Hartlen, K. D.; Athanasopoulos, A. P. T.; Kitaev, V. Facile preparation of highly monodisperse small silica spheres (15 to $>200 \mathrm{~nm}$ ) suitable for colloidal templating and formation of ordered arrays. Langmuir 2008, 24, 1714.

53. Fyfe, C. A. Solid State NMR for Chemists; C.F.C. Press; Guelph, Ontario, 1983.

54. Sadasivan, S.; Dubey, A. K.; Li, Y. Z.; Rasmussen, D. H. Alcoholic solvent effect on silica synthesis - NMR and DLS investigation. J. Sol-Gel Sci. Tech. 1998, 12, 5.

55. Harris, M. T.; Brunson R. R.; Byers C. H. The base-catalyzed-hydrolysis and condensationreactions of dilute and concentrated TEOS solutions. J. Non-Cryst. Solids 1990, 121, 397.

56. Green D. L.; Jayasundara, S.; Lam, Y. F.; Harris, M. T. Chemical reaction kinetics leading to the first Stober silica nanoparticles - NMR and SAXS investigation. J. Non-Cryst. Solids 2003, 315, 166.

57. Green, D. L.; Lin, J. S.; Lam, Y. F.; Hu, M. Z. C.; Schaefer, D. W.; Harris, M. T. Size, volume fraction, and nucleation of Stober silica nanoparticles. J. Colloid Interf. Sci. 2003, 266, 346.

58. Byers, C. H.; Harris, M. T.; Williams, D. F. Controlled microcrystalline growth-studies by dynamic laser-light-scattering methods. Ind. Eng. Chem. Res. 1987, 26, 1916.

59. Peace, B. W.; Mayhan, K. G.; Montle, J. F. Polymers from the hydrolysis of tetraethoxysilane. Polymer 1973, 14, 420.

60. Van Helden, A. K.; Jansen, J. W.; Vrij, A. Preparation and characterization of spherical monodisperse silica dispersions in non-aqueous solvents. J. Colloid Interf. Sci. 1981, 81, 354.

61. Bogush, G. H.; Tracy, M. A.; Zukoski, C. F. Preparation of monodisperse silica particles control of size and mass fraction. J. Non-Cryst. Solids 1988, 104, 95.

62. Rao, K. S.; Hami, K. E.; Kodaki, T.; Matsushige, K.; Makino, K. A novel method for synthesis of silica nanoparticles. J. Colloid Interf. Sci. 2005, 289, 125.

63. Ow, H.; Wiesner, U.; U.S. Patent Publication Number: US2004101822.

64. Jin, Y. H.; Lohstreter, S.; Pierce, D. T.; Parisien, J.; Wu, M.; Hall, C.; Zhao, J. X. J. Silica nanoparticles with continuously tunable sizes. Synthesis and size effects on cellular contrast Imaging. Chem. Mater. 2008, 20, 4411. 
Figures Captions:

Figure 1: DLS histograms for particles with sizes of 466, 255, 31, $12 \mathrm{~nm}$ (Exp. No; 2A, 2B, $2 \mathrm{~F}, 2 \mathrm{G})$, respectively. Amount of ethanol was varied between 60 and $5 \mathrm{ml}$ by keeping the amount of $0.1 \mathrm{ml}$ APTES-FITC, $1.2 \mathrm{ml}$ ammonia, $1.2 \mathrm{ml}$ TEOS constant.

Figure 2: $\quad$ Representative SEM images of FITC-conjugated to silica nanoparticles. Particle sizes are (A) $460 \mathrm{~nm},(B) 190 \mathrm{~nm},(C) 42 \mathrm{~nm}$ and (D) $30 \mathrm{~nm}$.

Figure 3: $\quad$ Plots showing dependence of particle size on initial amount of reagents. (A) ammonia (B) ethanol, (C) TEOS, (D) APTES-FITC. Size of particles exponentially decreases with increasing amount of ethanol, and increases with ammonia.

Figure 4: $\quad$ (A) ${ }^{29} \mathrm{Si} \mathrm{CP-MAS} \mathrm{NMR} \mathrm{and} \mathrm{(B)}{ }^{13} \mathrm{C}$ CP-MAS NMR spectra of particles.

Figure 5: $\quad$ Absorption ( $A$ and $C$ ) and fluorescence spectra ( $B$ and $D$ ) of FITC released by disintegrating $5 \mathrm{mg} / \mathrm{mL}$ of silica particles in $1 \mathrm{M} \mathrm{NaOH}$. Excitation wavelength is 490 $\mathrm{nm}$. The particles prepared by the set of experiments Exp. No. 1. and Exp. No. 2 were used. Disintegrated FITC molecules was separated by centifugation.

Figure 6: $\quad$ The graphs ( $A$ and $B$ ) were plotted for fluorescence intensity versus absorbance for the set of Experiment 1 ( $1 \mathrm{~A}$ to $1 \mathrm{E}$ in the Table 1 ) and the set of experiment 2 ( $2 \mathrm{~A}$ to $2 \mathrm{~F}$ ). 3D plots ( $\mathrm{C}$ and $\mathrm{D}$ ) of particle size versus fluorescence intensity and absorbance were shown. The correlation coefficient $R^{2}$ (for the exp. set of 1 )= $0.9522, R^{2}$ (for the exp. set of 2$)=0.9665$. The graphs on the left is related to effect of amount of ammonia, the plots on the right show effect of amount of ethanol.

Figure 7: The solvent effect: Fluorescence spectra of free FITC (left) dissolved in water and FITC conjugated to particles (right) dispersed in different solvents, dimethylformamide (DMF), ethanol (EtOH), and water $\left(\mathrm{H}_{2} \mathrm{O}\right)$.

Figure 8: Quenhing effect: The Stern-Volmer plots of free FITC and FITC-conjugated silica particles in the presence of quenchers $(A) \mathrm{I}^{-}(B) \mathrm{Cu}^{2+}$ ions.

Figure 9: The $\mathrm{pH}$ dependence of fluorescence spectra for free FITC (on the left) and particles (on the right). The $\mathrm{pH}$ of the solution was varied from 7 to 13 . The $\mathrm{pH}$ dependence of fluorescence intensity is shown by taking the intensity at $\mathrm{pH} 7$ as reference. Solutions with higher $\mathrm{pH}$ values cause a reduction in the fluorescence intensity of FITC.

Figure 10: Assessment of photostability of silica particles by continuous illumination by a pulsed Xe lamp. Amount of FITC encapsulated in particles varied but the size of particles is constant around $30 \mathrm{~nm}$. Black, Exp. No. 4E; red, Exp No. 4D; blue, Exp. No. 4C; green, Exp. No. 4B.

Figure 11: Cell viability assayed by MTT for the cell lines MCF 7 and PC3. Variables are particles with different sizes $(12,48,251 \mathrm{~nm})$, incubation times $(24,48,72 \mathrm{~h})$, and dosages $(1-1000 \mu \mathrm{g} / \mathrm{ml})$. 
Figure 1
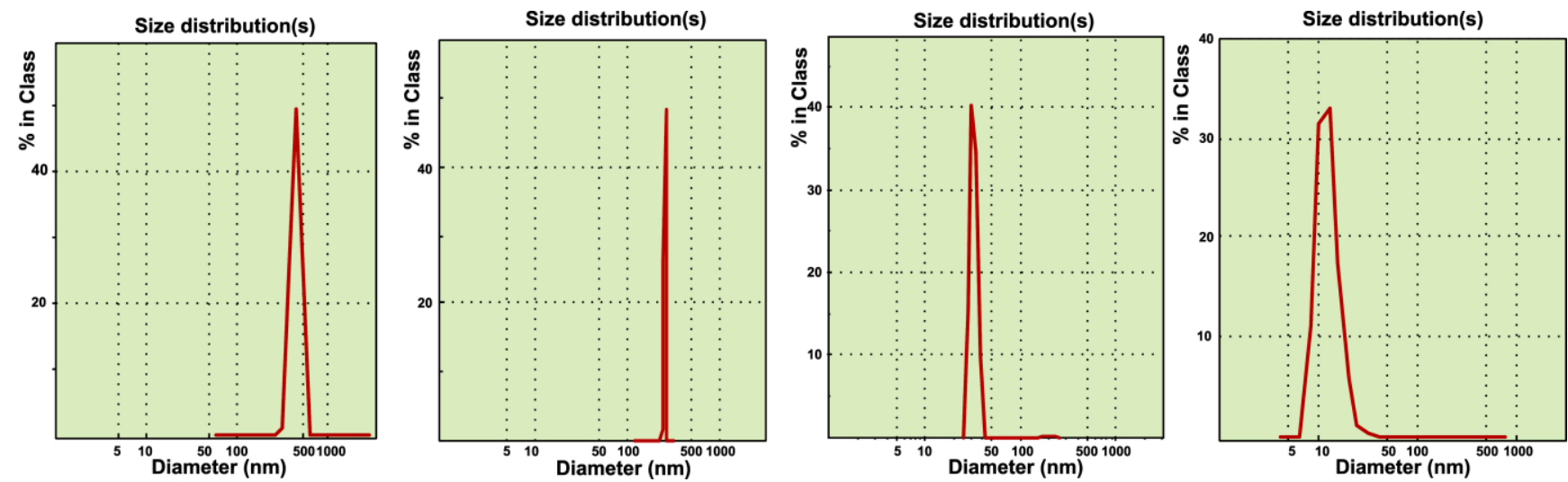
Figure 2
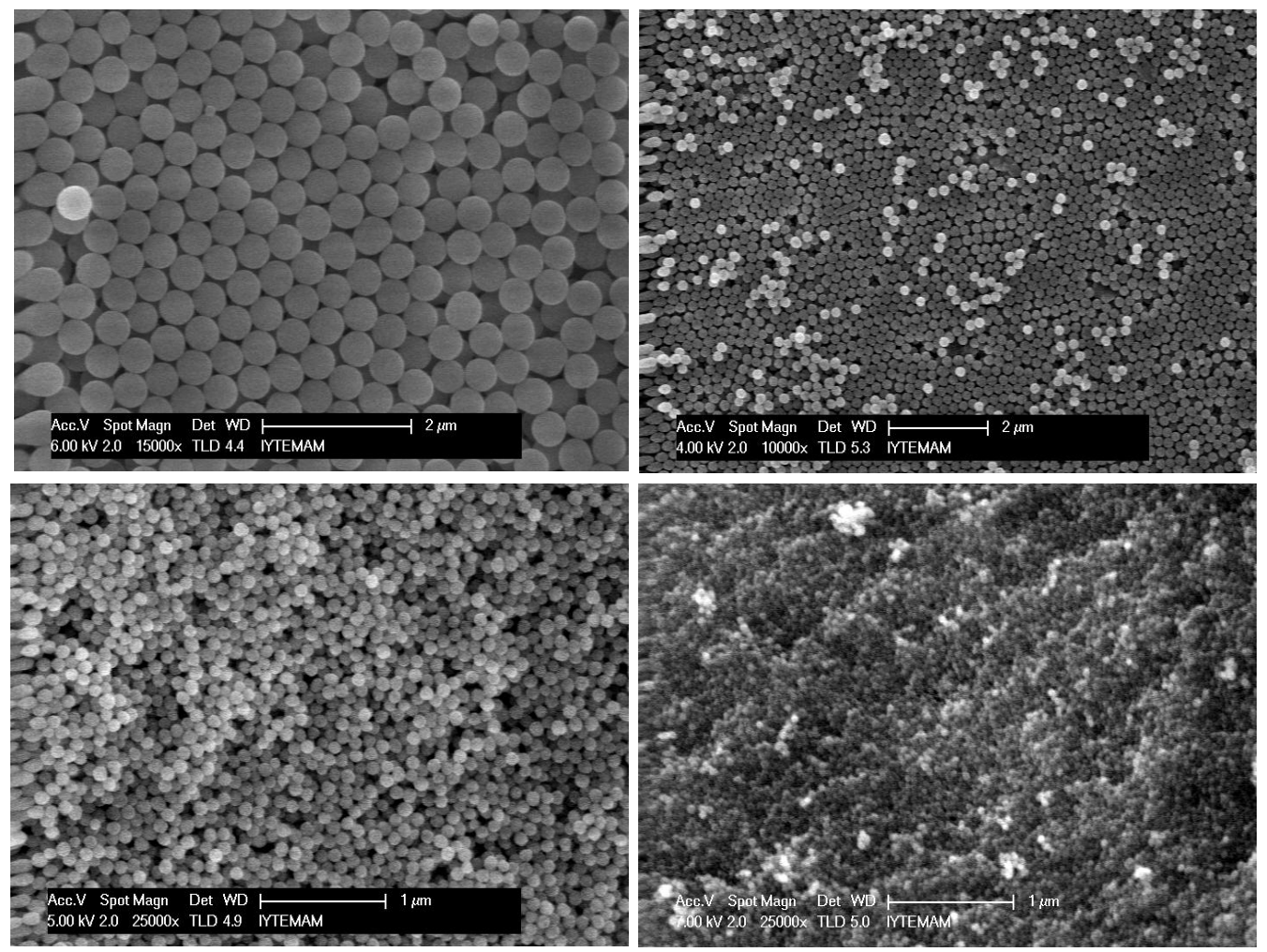
Figure 3
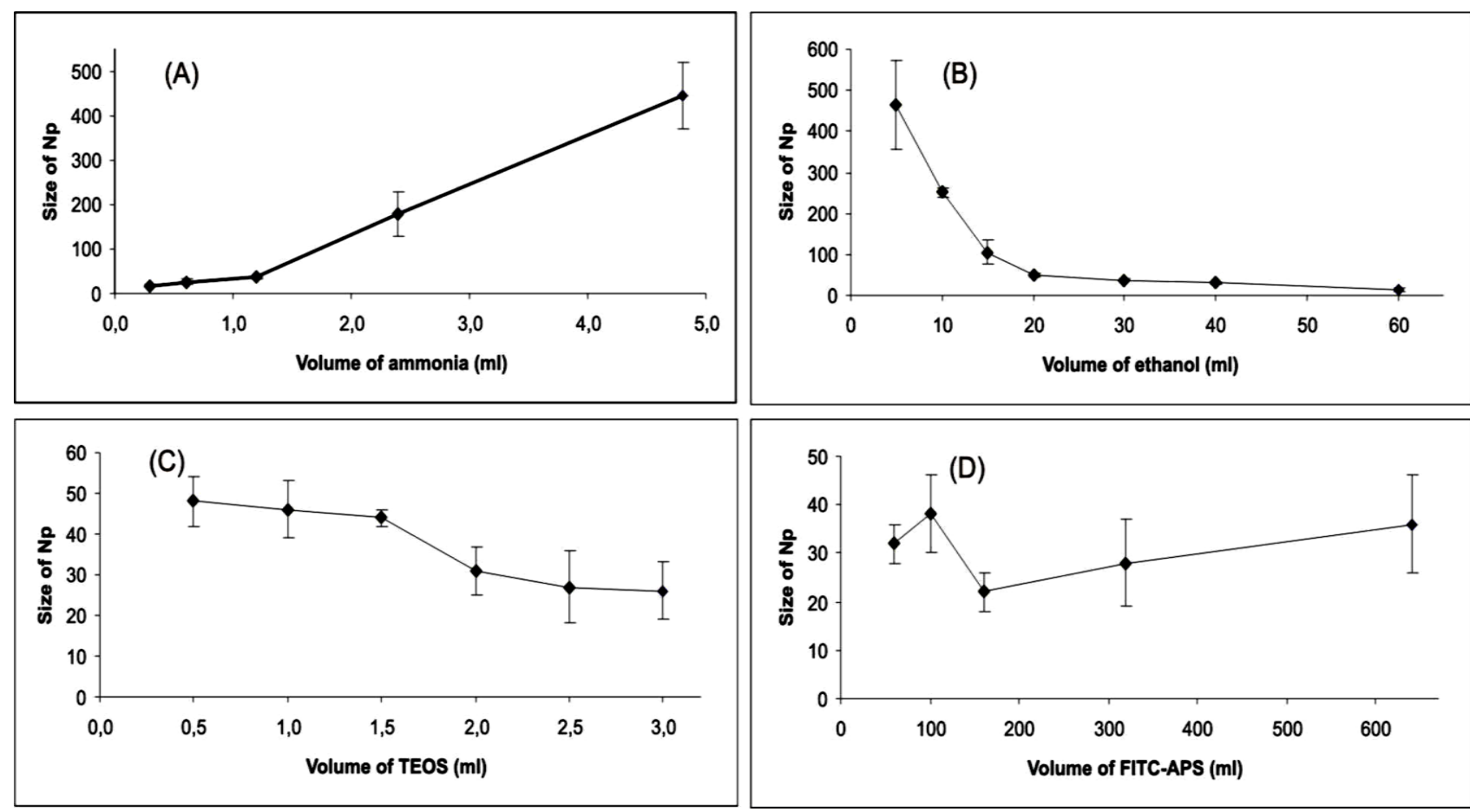
Figure 4

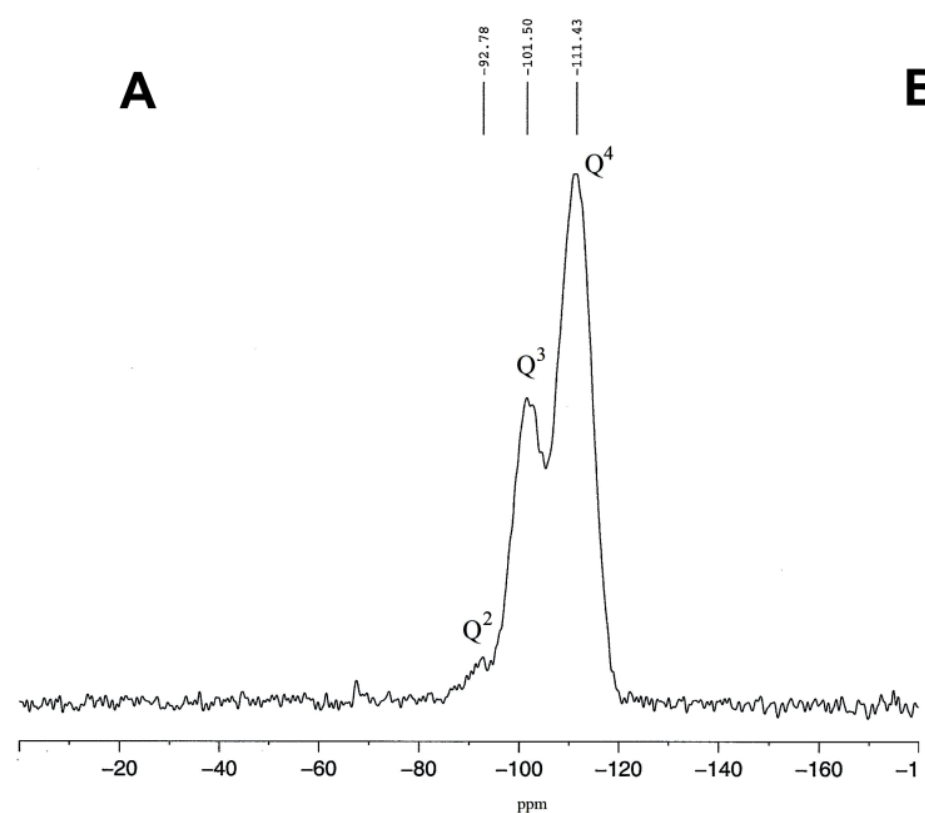

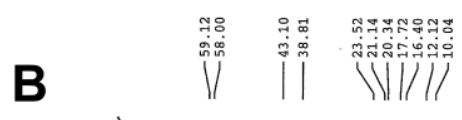

$\stackrel{\backslash}{\mathrm{Si}-} \stackrel{1}{\mathrm{CH}_{2}}-\stackrel{2}{\mathrm{CH}_{2}}-\stackrel{3}{\mathrm{C}} \mathrm{H}_{2}-\mathrm{NH}_{2}$

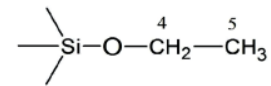

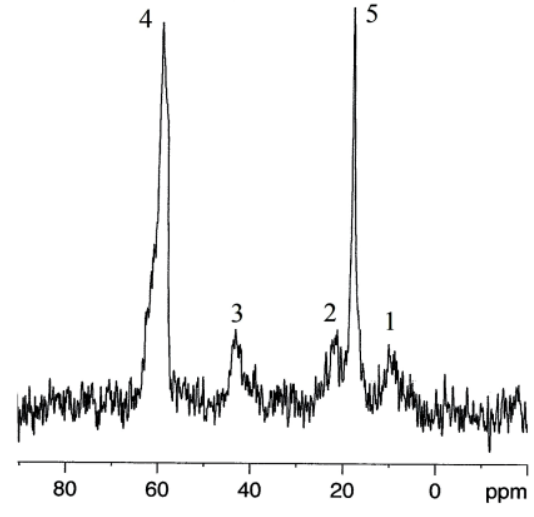


Figure 5
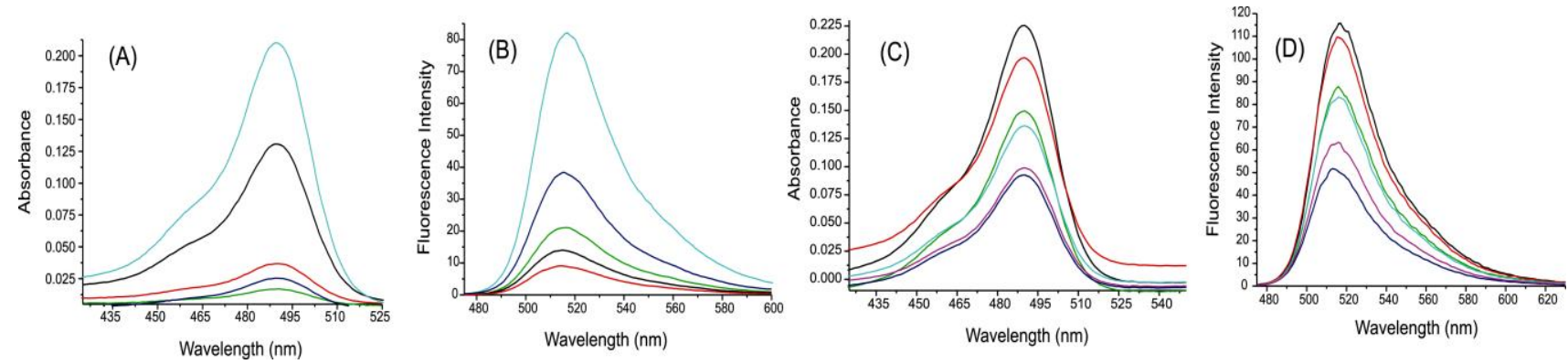
Figure 6
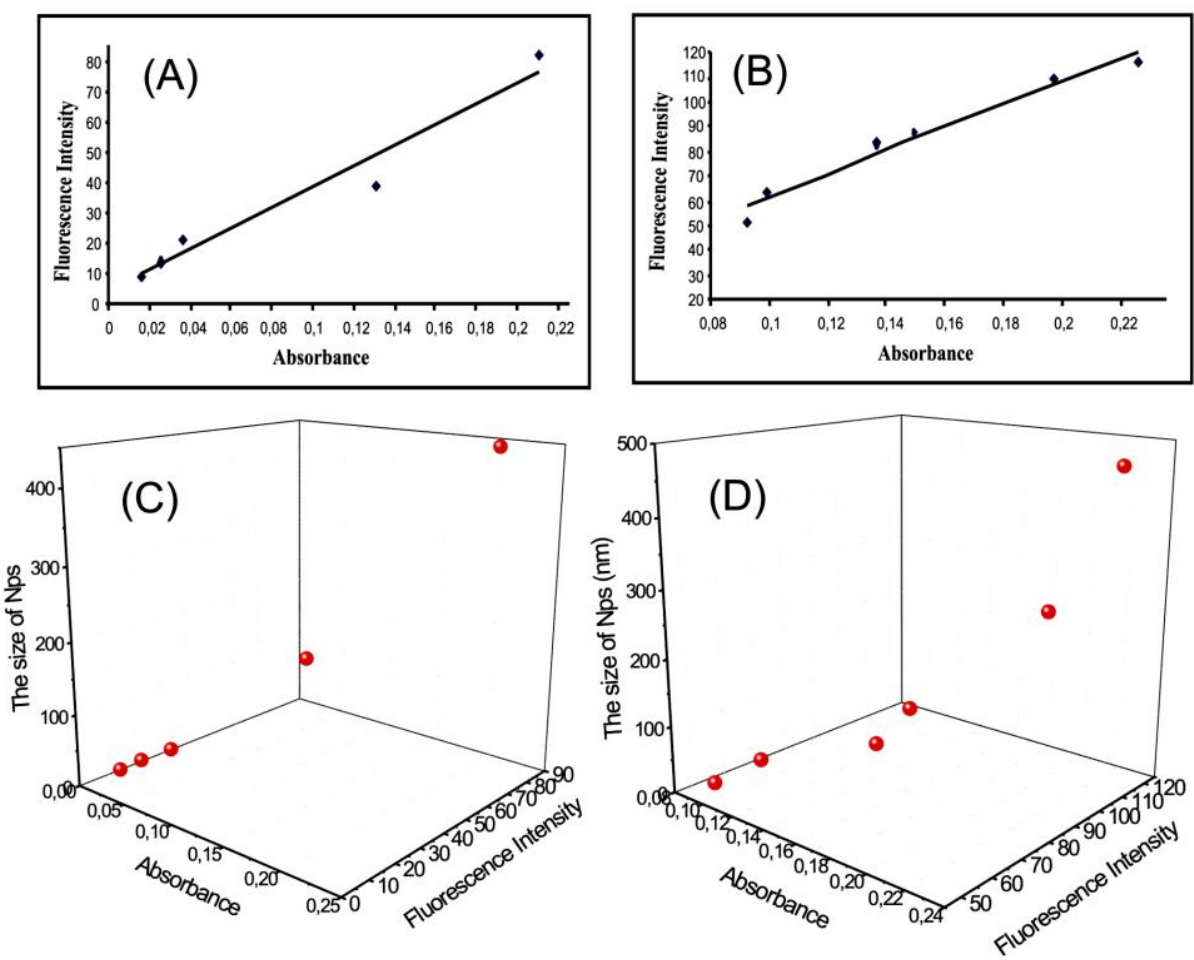
Figure 7
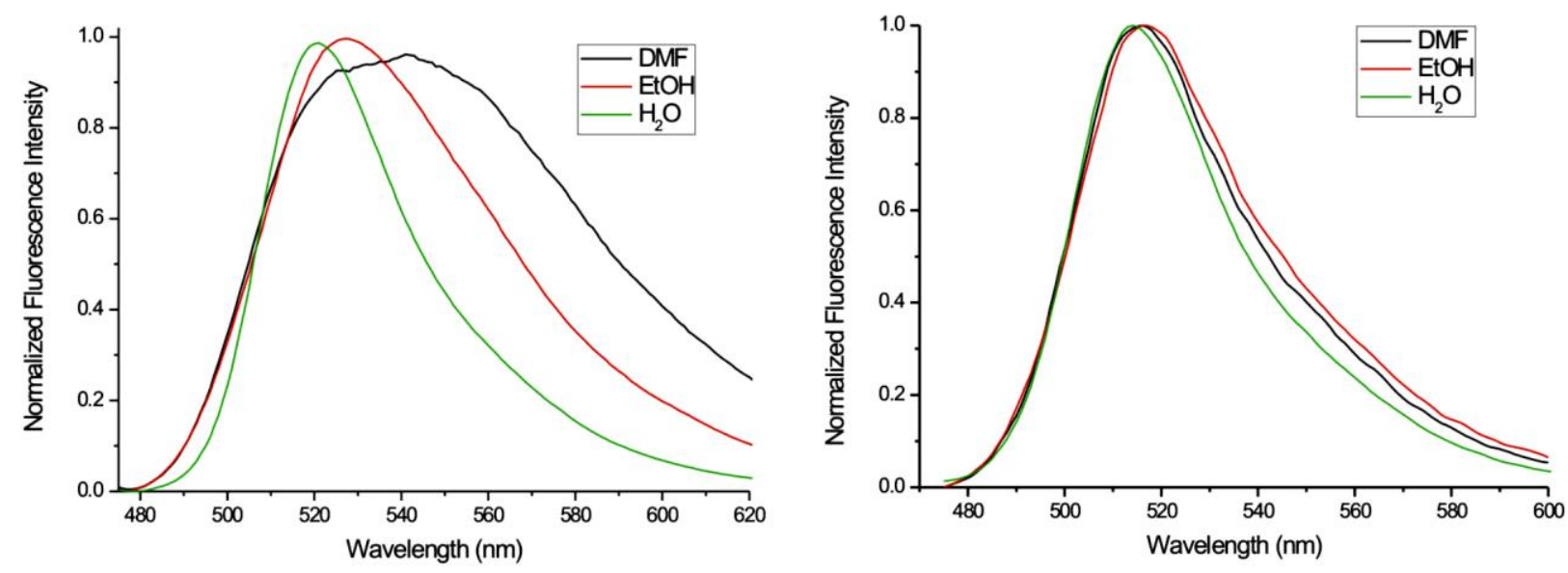
Figure 8
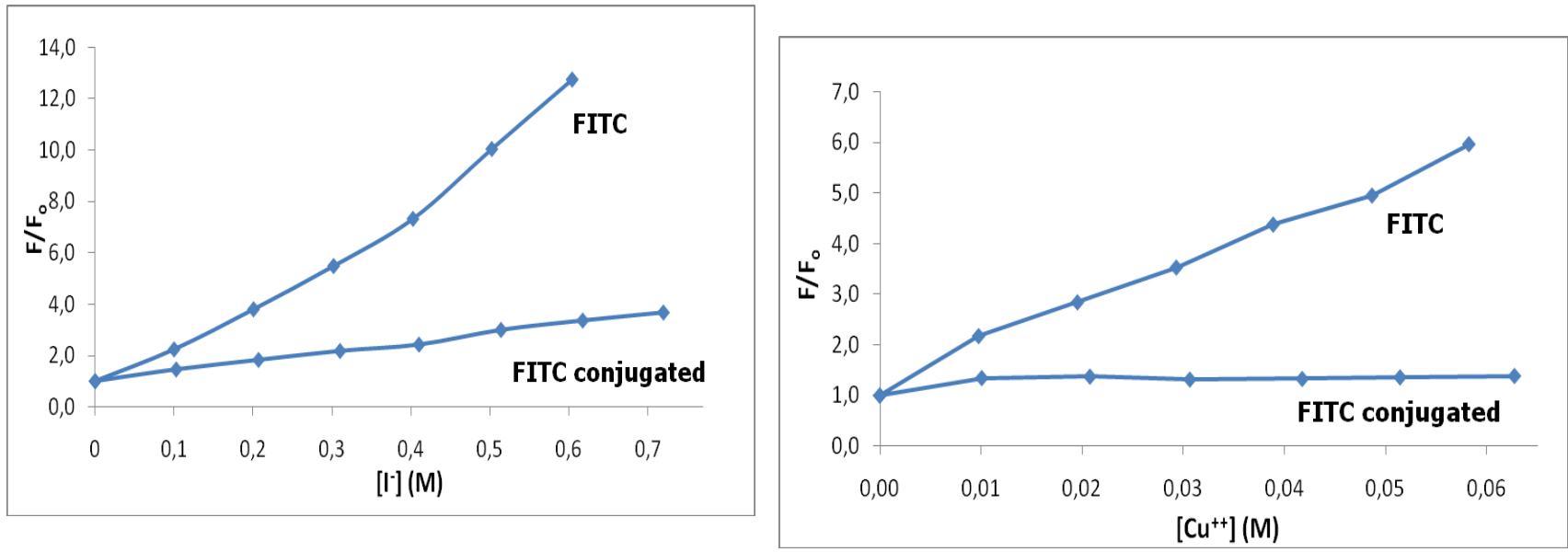
Figure 9
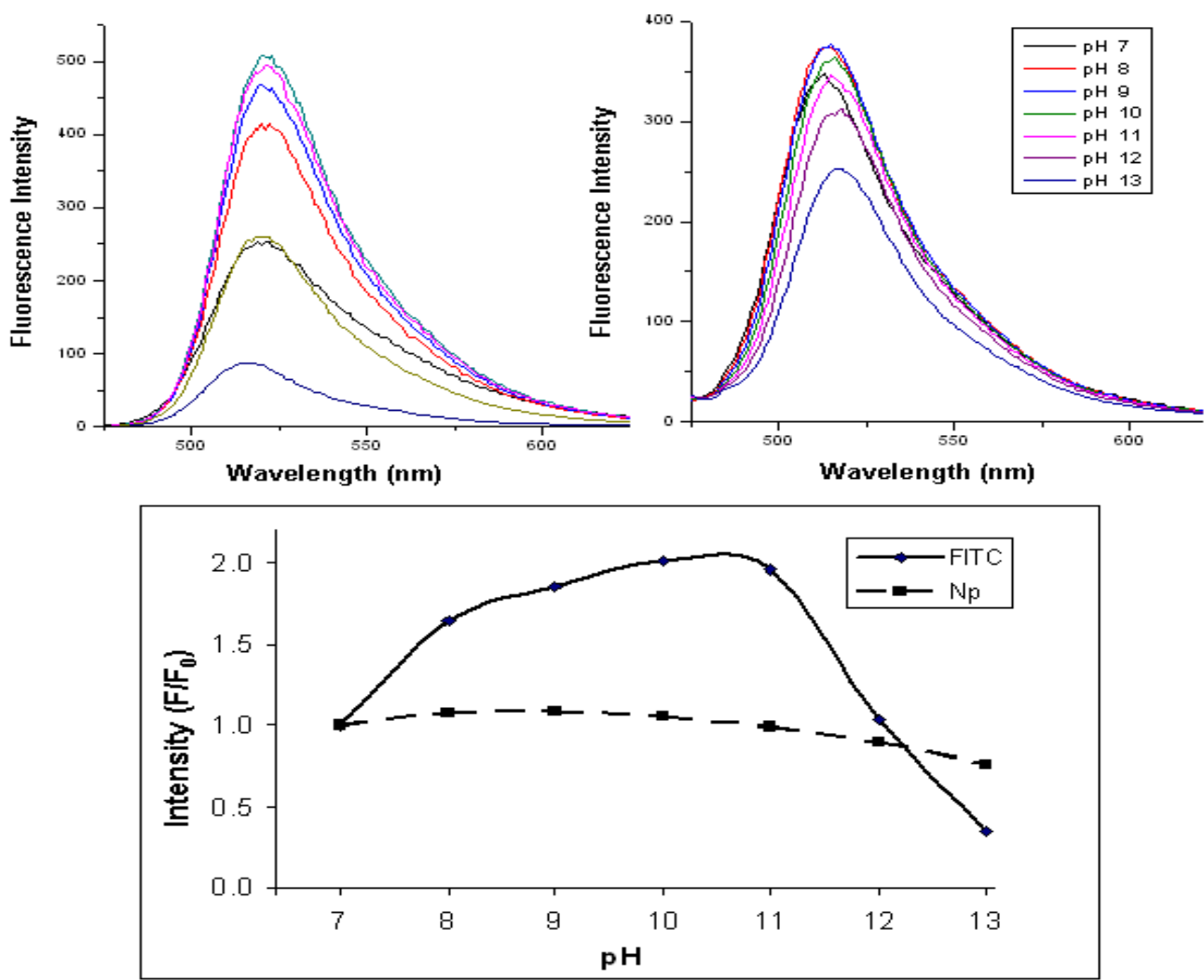
Figure 10

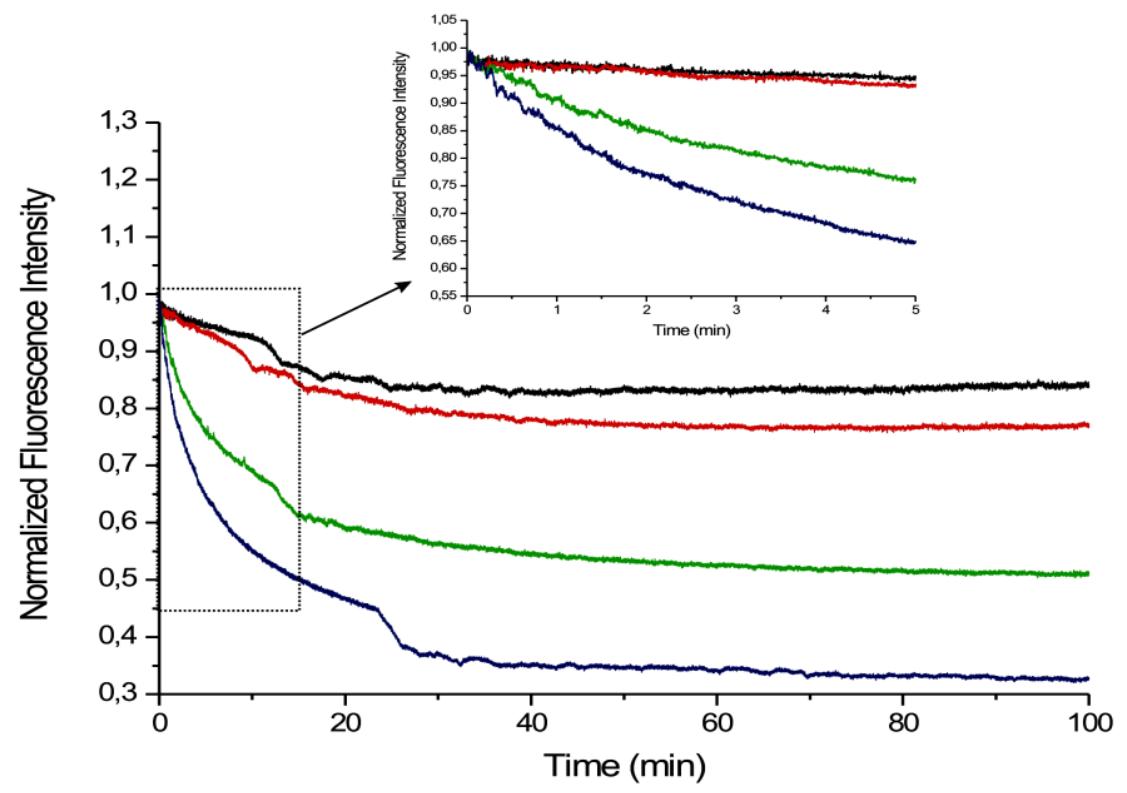


Figure 11

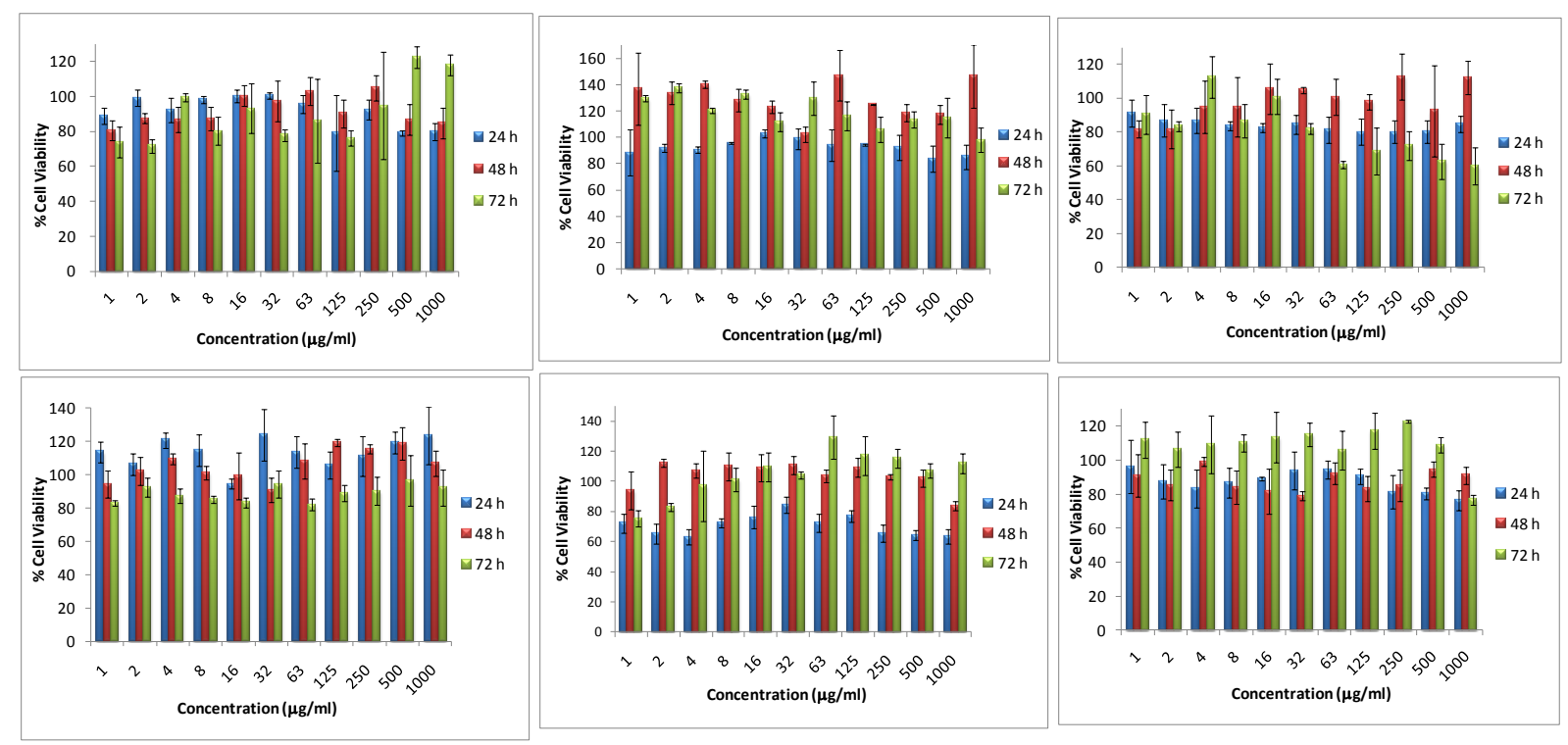

